\title{
Formação de Adultos Trabalhadores
}

\author{
Celso Voto Akil \\ Universidade Severino Sombra, Mestrado Profissional em Educação \\ Matemática \\ celsoakil@gmail.com \\ Janaína Veiga \\ Universidade Severino Sombra, Mestrado Profissional em Educação \\ Matemática \\ janainavcarvalho@gmail.com \\ Ana Maria Severiano de Paiva \\ Universidade Severino Sombra, Mestrado Profissional em Educação \\ Matemática; Universidade Bandeirante de São Paulo, Pós- \\ Doutoramento \\ anaseveriano@uol.com.br.
}

Resumo: Apresenta-se parte da análise do contexto legal que respalda uma formação profissional que utilize e suscite a valorização de saberes não escolares, constantes, em sua totalidade, na dissertação elaborada para o projeto de pesquisa - Matemática e Direitos Humanos- desenvolvido no âmbito do Programa de Pós-Graduação Stricto Sensu em Educação Matemática da Universidade Severino Sombra (Vassouras, Rio de Janeiro). O objetivo do trabalho consistiu em investigar a formação de adultos trabalhadores em sistemas de alta tensão de distribuidoras de energia elétrica, constituídos de subestações elevadoras (PCHs), ou rebaixadoras (distribuidoras), e em linhas de transmissão de transporte de energia elétrica (em ambas) localizadas no estado do Rio de Janeiro. Como referencial teórico, partiu-se das ideias de Ubiratan D'Ambrosio e Paulo Freire, cujas reflexões nos permitiram atribuir significados aos saberes dos operários adquiridos fora dos espaços oficiais de formação e qualificação. Metodologicamente, o estudo teve uma abordagem qualitativa, com seleção de exemplos e práticas de tarefas, estabelecendo-se paralelo entre o saber científico e o dos operários, bem como se procedeu a uma análise criteriosa de documentos da legislação educacional brasileira, relacionados à educação profissional. Como resultado, aponta-se que é no trabalho, pela experiência, que se constrói o saber daqueles que não puderam frequentar os bancos escolares por um tempo suficiente que lhes permitisse apreender as "leis da engenharia". É "o saber de experiência feito" (apresentado por Freire) que, ao se confrontar cotidianamente com o desgaste físico, com o cansaço, possibilita a adultos trabalhadores vivenciarem a formação durante e no trabalho.

Palavras-chave: Educação profissional. Formação no trabalho. Saber. Experiência. 


\title{
Formation of Adult-Workers
}

\begin{abstract}
It presents the analysis of the legal framework that supports vocational training to use and raise the valuation of non-school knowledge, contained in its entirety, prepared for the dissertation research project developed under the Program of Post-graduate-Mathematics e Human Rights-studies in Mathematics Education at the University Severino Sombra (Vassouras, Rio de Janeiro). The objective of this research was to investigate the formation of adult-workers in high-voltage electric power distribution, consisting of substations (SHP) or rebaixadoras (distributors), and transmission lines carrying electricity (in both ) located in the state of Rio de Janeiro. The theoretical framework of ideas broke Ubiratan D'Ambrosio and Paulo Freire, whose ideas have allowed us to assign meaning to knowledge workers purchased outside the official spaces of training and qualifications. Methodologically, the study was a qualitative approach with the selection of examples and practical tasks, establishing parallel between scientific knowledge and knowledge workers, and it undertook a thorough analysis of documents from the Brazilian educational legislation relating to vocational education. As a result, it is noted that the work is, by experience, which builds the knowledge of those who could not attend the school benches for a time sufficient to allow them to learn the "laws of engineering." It is "knowledge of experience" (presented by Freire) that, when confronted with the daily physical fatigue, with fatigue, allows adults to experience-workers during training and at work.
\end{abstract}

Keywords: Professional education. Formation on the job. Know. Experience.

\section{Introdução}

O objeto da investigação ora apresentada são as práticas de "formação" - os "saberes de experiência feitos" - de adultos trabalhadores em uma concessionária de energia elétrica de pequena central hidrelétrica $(\mathrm{PCH})$ na execução de tarefas de manutenção programada e, principalmente, de eventos que surgem durante os serviços de atendimento emergencial como defeitos elétricos, mecânicos e civis.

Em situações anormais ou imprevisíveis, as decisões têm de ser tomadas no campo, baseadas em análise realizada no momento da ocorrência. São os trabalhadores ou operários "sem escolarização formal sobre as leis da engenharia" que, por meio de contato telefônico ou por rádio de telecomunicação com os engenheiros de plantão na administração central da companhia, afastada da instalação, encontram possíveis soluções para os problemas.

Nesses momentos, os sujeitos da ação - operários e engenheiros - praticam, sem saber, princípios freireanos (Freire, 1996). Educador e educando se alternam e complementam. Aquele que ensina - o professor-engenheiro - não é superior, melhor ou mais inteligente que o aluno-operário. Ensinar e aprender são faces da mesma ação. 
O professor-engenheiro domina conhecimentos que o "aluno-operário" ainda não conhece, mas no confronto da teoria com a prática, do que se aprende nos espaços formais de formação, com o que se coloca em "uso" no campo específico de uma ação, o que se observa é que ambos - engenheiro e operário - tornam-se sujeitos da aprendizagem. Aquele que ensina, diante do conhecimento do aluno-operário, que provém da prática, reelabora o que sabe ao ensinar, apropriando-se do saber de quem detém a prática.

\section{O Contexto Legal da Formação de Trabalhadores}

A Lei n. ${ }^{\circ}$ 9.394, de 20.12.1996 (Brasil, 1996), que institui as diretrizes e bases da educação nacional, estabelece em seu artigo 39, o objetivo da educação profissional, assim como enfatiza a sua associação transversal com outros espaços da formação: "A educação profissional, integrada às diferentes formas de educação, ao trabalho, à ciência e à tecnologia, conduz ao permanente desenvolvimento de aptidões para a vida produtiva".

No parágrafo único desse artigo são garantidas as condições de acessibilidade ao ensino profissional, estabelecendo-se as origens do postulante em relação à formação anterior e faixa etária: "O aluno matriculado ou egresso do ensino fundamental, médio e superior, bem como o trabalhador em geral, jovem ou adulto, contará com a possibilidade de acesso à educação profissional".

Observa-se, assim, que o referido artigo abre inúmeras possibilidades de constituição da matriz curricular, que deverá valorizar a formação necessária e as áreas de atuação desses profissionais. Sobre esse artigo e a LDBEN em geral, Cêa (2006, p. 2) comenta:

\footnotetext{
Na LDB 9.394/96, a educação profissional é apresentada como uma modalidade educacional (Título V, Capítulo III) voltada para o "desenvolvimento de aptidões para a vida produtiva" (Art. 39), incorporando a tendência indicada anteriormente. Ao tratar especificamente da educação profissional, a LDB indica algumas possibilidades de organização: integração com as diferentes formas de educação (Parágrafo único do Art. 39) [...].
}

No artigo 40 dessa lei, estabelece-se que a "educação profissional será desenvolvida em articulação com o ensino regular ou por diferentes estratégias de educação continuada, em instituições especializadas ou no ambiente de trabalho".

Corroborando essa determinação, o artigo 41 destaca: "O conhecimento adquirido na educação profissional, inclusive no trabalho, poderá ser objeto de avaliação, reconhecimento e certificação para prosseguimento ou conclusão de estudos".

Com o objetivo de regulamentar o contido no artigo 39 da LDBEN, o Decreto n. ${ }^{\circ} 5.154$, de 23 de julho de 2004 (Brasil, 2004), estabelece:

Art. $1^{\circ}$ A educação profissional, [...] observadas as diretrizes curriculares nacionais definidas pelo Conselho Nacional de Educação, será desenvolvida por meio de cursos e programas de:

I - formação inicial e continuada de trabalhadores;

II - educação profissional técnica de nível médio; e

III - educação profissional tecnológica de graduação e de pós-graduação. 
Ao destacar, no inciso I, de seu artigo 1. ', a formação inicial e continuada dos trabalhadores, o decreto supramencionado estimula uma nova "organização" do ensino, que deverá se dar "por áreas profissionais, em função da estrutura socio-ocupacional e tecnológica", prevendo a "articulação de esforços das áreas da educação, do trabalho e emprego, e da ciência e tecnologia" (Brasil, 2004, art. 2. ${ }^{\circ}$, incisos I, II).

Essas deliberações representam um marco que abrange o arcabouço da formação dos trabalhadores, viabilizando a utilização de conceitos não convencionais de formação através do trabalho, estabelecendo, ainda, em seu artigo $3 .^{\circ}$, que:

\footnotetext{
Os cursos e programas de formação inicial e continuada de trabalhadores, referidos no inciso I do art. $1^{\circ}$, incluídos a capacitação, o aperfeiçoamento, a especialização e a atualização, em todos os níveis de escolaridade, poderão ser ofertados segundo itinerários formativos, objetivando o desenvolvimento de aptidões para a vida produtiva e social.
}

Objetivando não deixar dúvidas quanto à referida formação, no parágrafo $1 .^{\circ}$ do artigo 3..$^{\circ}$ desse decreto conceitua-se itinerário formativo como "o conjunto de etapas que compõem a organização da educação profissional em uma determinada área". Essa forma de organização possibilitaria "o aproveitamento contínuo e articulado dos estudos". Para tanto, o parágrafo $2 .^{\circ}$ desse artigo define que os cursos específicos da educação profissional "articular-se-ão, preferencialmente, com os cursos de educação de jovens e adultos [...]", modalidade de ensino da educação básica. Para estes, a qualificação para o trabalho, associada à ampliação da escolarização, adquire significado se articulada com o itinerário formativo e associada à formação no trabalho, na valorização dos saberes.

Coerente com as diretrizes emanadas da legislação supramencionada, o Ministério da Educação (MEC) lança, em junho de 2008, o "Catálogo Nacional de Cursos Técnicos" (Brasil, 2008).

O ministro da Educação afirma, na "Apresentação", que o Catálogo Nacional para cursos técnicos é "parte da política de desenvolvimento e valorização da educação profissional e tecnológica de nível médio", configurando-se "como importante mecanismo de organização e orientação da oferta nacional dos cursos técnicos de nível médio [...] propiciando uma formação técnica contextualizada com os arranjos socioprodutivos locais, gerando novo significado para formação, em nível médio, do jovem brasileiro". Desse modo, propicia, "aos estudantes, um guia de escolha profissional e, ao setor produtivo, maior clareza entre oferta educativa e sua relação com os postos de trabalho" (Brasil, 2008, p. 5).

O Catálogo agrupa os cursos conforme suas características científicas e tecnológicas em 12 eixos tecnológicos, que somam 185 possibilidades de oferta de cursos técnicos (Brasil, 2008, p. 7).

Os sujeitos da pesquisa enquadram-se nas especializações do Eixo Tecnológico: Controle e Processos Industriais (Brasil, 2008, p. 60), 
[...] que compreende tecnologias associadas a processos mecânicos, eletroeletrônicos e físico-químicos. Esse eixo abrange ações de instalação, operação, manutenção, controle e otimização em processos, contínuos ou discretos, localizados predominantemente no segmento industrial, contudo alcançando também em seu campo de atuação instituições de pesquisa, segmento ambiental e de serviços.

No caso específico das concessionárias e pequenas centrais hidrelétricas, essas organizações atuam na área de serviços ou produção e os cursos técnicos compatíveis são: Técnico em Eletromecânica, Técnico em Mecânica e Técnico em Eletrotécnica, funções às quais almejam, naturalmente, operários eletricistas, mecânicos e eletromecânicos dessas companhias como o máximo de suas carreiras.

\section{O "Professor-Engenheiro" e o "Aluno-Trabalhador"}

No que se refere à capacitação por competências (necessárias aos operários), Alexim e Lopes (2003, p. 3) afirmam: "O ideal de reconhecer a experiência adquirida/desenvolvida pelo trabalhador na atividade prática de trabalho, no ambiente de trabalho, vem de longe e obedece a diferentes intenções".

Para Kuenzer (1988, apud Alexim e Lopes, 2003, p. 3), “o trabalhador vai elaborando um saber eminentemente prático, fruto de suas experiências empíricas, que, sendo parciais em função da divisão técnica do trabalho, originam um saber igualmente parcial e fragmentado.

Com relação à certificação profissional com base no artigo 41 da LDBEN n. ${ }^{\circ}$ 9.346/96, Rocha (2004, p. 2) assegura que, no Brasil,

\footnotetext{
[...] a discussão sobre certificação profissional baseada em competências está associada à noção de respeito à diversidade, que passou a se tornar obrigatória no debate sobre políticas de desenvolvimento sustentado, de resgate dos direitos humanos econômicos, sociais e culturais, de promoção de igualdade e de combate a todas as formas de discriminação, em especial a que se manifesta no mundo do trabalho, assumindo que essa é uma dimensão fundamental para se construir um novo modelo de educação no país, focado no enfrentamento da exclusão social e na construção da cidadania. [...].
}

O autor afirma que um país como o Brasil - multicultural - deverá considerar saberes de diferentes sujeitos sociais (diversidade) em uma certificação profissional por competência. Como exemplo, temos o saber indígena sobre as plantas medicinais da floresta. Como pesquisar essas "ervas" sem a competência do índio ou do "caboclo" ou do "sertanejo", esses dois últimos, produtos étnicos dessa matriz?

Esses dois conceitos - certificação e diversidade incorporam orientação das diretrizes do Plano Nacional de Direitos Humanos (Brasil, 2007) e da Convenção n. ${ }^{\circ} 111$ da Organização Internacional do Trabalho (OIT), assumindo que "[...] a qualificação profissional deve atender a população economicamente ativa (PEA) em toda sua diversidade, sem discriminação de qualquer natureza: idade, sexo, raça/cor, escolaridade, aptidões físicas e mentais" (Alexim et al., 2002, p. 10). 
Segundo Rocha (2004, p. 2): “[...] a Certificação Profissional baseada em Competências é considerada como uma das inovações do conjunto de mudanças introduzidas nas reformas da educação profissional do país”, cujo objetivo, de modo geral, “[...] é o reconhecimento formal dos conhecimentos, habilidades, atitudes e competências do trabalhador, requeridos pela sociedade e definidos em termos de padrões ou normas acordadas previamente, independentemente da forma como foram adquiridos".

Para a Organização Internacional do Trabalho, em seu Glossário de Termos Técnicos (Alexim e Brígido, 2002, p. 20), a certificação de competências profissionais pode ser definida como:

\begin{abstract}
Reconhecimento ou o atestado expedido por órgão credenciado, da competência do trabalhador nos conhecimentos, habilidades e atitudes, em determinadas funções profissionais, independentemente do fato de ter, ou não, cursado um sistema regular de formação ou ter adquirido a experiência na prática do trabalho. Caracteriza-se por ser voluntária, realizada por organismos especializados, ou por uma empresa, segundo enunciados padronizados e reconhecidos, assegurando imparcialidade e acessibilidade, facilitando a mobilidade laboral através da eliminação de barreiras de ingresso ao mercado de trabalho. Deve ser centrada no que o trabalhador deve saber fazer.
\end{abstract}

Os operários podem ter reconhecidas, pelo Conselho Regional de Engenharia e Arquitetura (CREA), as competências na função da profissão, fundamentadas ou originadas da apropriação de saberes obtidos no trabalho. Rocha (2004) apresenta os caminhos a serem adotados para a certificação profissional baseada em competências (Figura 1).

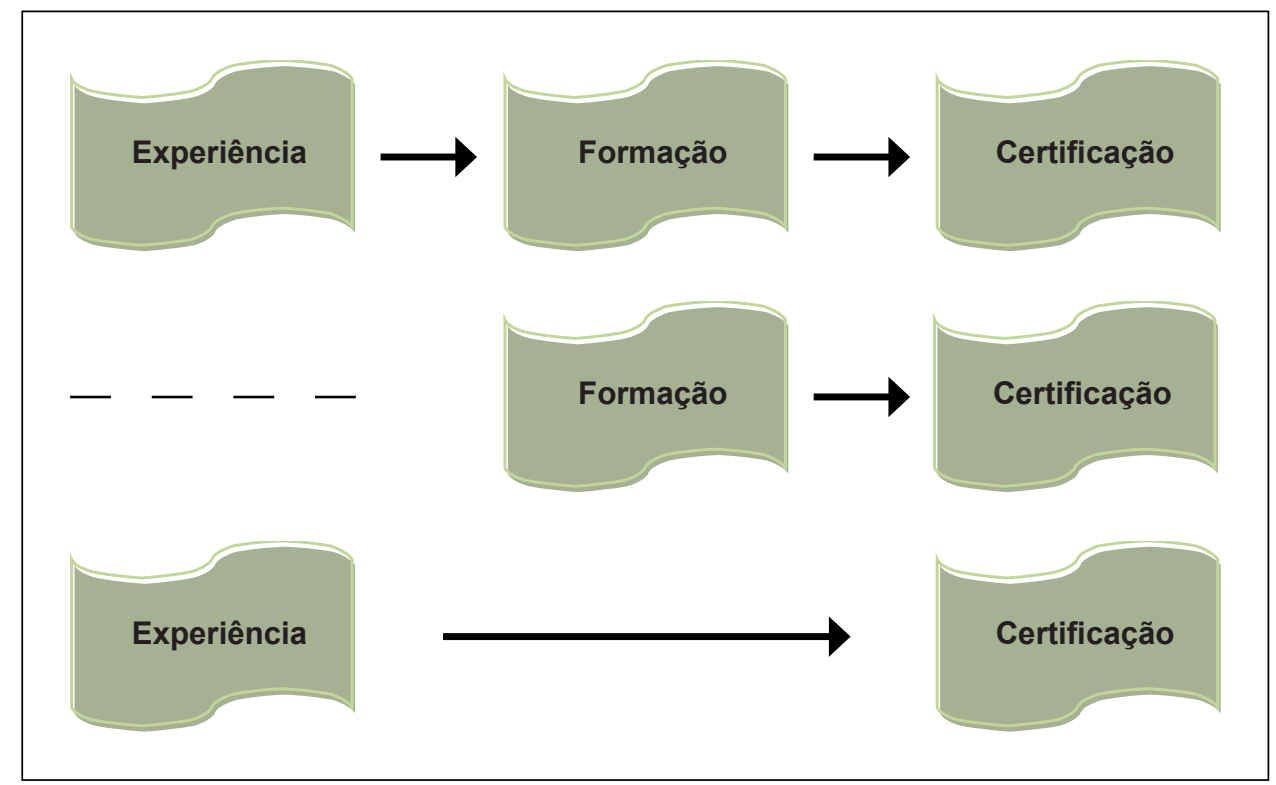

Figura 1. Esquema da certificação Profissional baseada em Competências Fonte: (Rocha, 2004, p. 3) 
Segundo Rocha (2004, p. 4), “[...] por competência profissional entende-se a capacidade de mobilizar, articular e colocar em ação valores, habilidades e conhecimentos necessários para o desempenho eficiente de atividades requeridas pela natureza do trabalho". Para esse autor, "as discussões sobre a certificação profissional baseada em competências estão presentes no mundo todo" (Quadro 1).

\section{Quadro 1: A Certificação Profissional baseada em Competências no Mundo Fonte: (Rocha, 2004, p. 4-5)}

\begin{tabular}{|c|c|}
\hline Argentina & $\begin{array}{l}\text { Existe um Programa de Formação e Certificação de Competências para o Trabalho no Ministério } \\
\text { do Trabalho da Argentina. Atualmente, eles discutem a criação de um sistema nacional de } \\
\text { certificação profissional. }\end{array}$ \\
\hline Inglaterra & $\begin{array}{l}\text { Existe um Conselho Nacional de Qualificações Vocacionais (National Council Vocational } \\
\text { Qualifications) com funções reguladoras e de fiscalização e ainda comitês de normatização no } \\
\text { setor industrial (lead industry bodies), organismos certificadores (awarding bodies) e centros } \\
\text { avaliadores. No sistema inglês, mais que encontrar uma definição de competência profissional, } \\
\text { o conceito se encontra latente na estrutura do sistema normalizado. A competência profissional } \\
\text { se identifica nas normas através da definição de elementos de competência (êxitos profissionais } \\
\text { que um trabalhador é capaz de conseguir), critérios de desempenho e o campo de aplicação e os } \\
\text { conhecimentos requeridos. Nesse sistema foram definidos cinco níveis de competências. }\end{array}$ \\
\hline França & $\begin{array}{l}\text { Há um Conselho Interministerial com poderes para autorizar especialistas que assinam e garantem } \\
\text { os certificados, mantendo diferenciados os âmbitos nacionais e regionais e adotando os exames } \\
\text { teóricos e práticos com uso de simuladores. }\end{array}$ \\
\hline Espanha & $\begin{array}{l}\text { Utiliza um instituto de qualidade e avaliação para dar apoio técnico às iniciativas. A formação } \\
\text { profissional ocupacional é ministrada pelo Instituto Nacional de Emprego (INEM), que outorga } \\
\text { certificados e edita um "repertório de certificados de profissionalização", funcionando como apoio } \\
\text { para as empresas na formação contínua. }\end{array}$ \\
\hline México & $\begin{array}{l}\text { Criou o Conselho Nacional de Normatização e Certificação (CONOCER), entidade que regula } \\
\text { e promove a certificação através de organismos certificadores que, por sua vez, podem instituir } \\
\text { centros de avaliação. Para os mexicanos, a capacidade produtiva de um indivíduo que se define } \\
\text { e pode ser medida em termos de nível de desempenho em um determinado contexto profissional, } \\
\text { e não apenas de conhecimentos, habilidades, destrezas e atitudes; estas são necessárias, porém } \\
\text { não suficientes por si só para um desempenho efetivo. }\end{array}$ \\
\hline Alemanha & $\begin{array}{l}\text { Reconhece que possui competência profissional quem dispõe dos conhecimentos, destrezas } \\
\text { e atitudes necessárias para exercer uma profissão, pode resolver os problemas profissionais } \\
\text { de forma autônoma e flexível, está capacitado para colaborar em entorno profissional e na } \\
\text { organização. }\end{array}$ \\
\hline Austrália & $\begin{array}{l}\text { Acompetência se define como uma complexa estrutura de atributos necessários para o desempenho } \\
\text { de situações específicas. É uma complexa combinação de atributos (conhecimentos, atitudes, } \\
\text { valores e habilidades) e as tarefas que se tem que desempenhar em determinadas situações. }\end{array}$ \\
\hline Portugal & $\begin{array}{l}\text { A Certificação Profissional tem como objetivo principal garantir que um trabalhador tem as } \\
\text { competências adequadas para desempenhar uma determinada profissão. Pretende ainda } \\
\text { facilitar a livre circulação de trabalhadores na União Europeia e promover a transparência } \\
\text { das qualificações, permitindo uma empregabilidade mais ajustada. Através da emissão de um } \\
\text { Certificado de Aptidão Profissional (CAP), pela Entidade Certificadora, o trabalhador vê as suas } \\
\text { competências reconhecidas para exercer determinada profissão, o que permite a sua valorização } \\
\text { e dignificação profissional. }\end{array}$ \\
\hline BRASIL & $\begin{array}{l}\text { As iniciativas para a criação de um sistema nacional de certificação estão a cargo do Ministério } \\
\text { do Trabalho e Emprego, do Ministério da Educação, da OIT e de vários organismos nacionais de } \\
\text { formação profissional (SENAC, SESI, ABRAMAN, entre outros). }\end{array}$ \\
\hline
\end{tabular}


A certificação profissional baseada em competências, para os operários, tem importância no cumprimento da "NR 10: Segurança nas Instalações e Serviços em Eletricidade", do Ministério do Trabalho e Emprego (Brasil, 2005). Sem essa certificação, o sujeito fica proibido de exercer atividades nos cenários da pesquisa.

A NR 10 tem como objetivo e campo de aplicação estabelecer os "[...] requisitos e condições mínimas objetivando a implementação de medidas de controle e sistemas preventivos, de forma a garantir a segurança e a saúde dos trabalhadores que, direta ou indiretamente, interajam em instalações elétricas e serviços com eletricidade".

As áreas em que essa norma regulamentadora do trabalho é aplicada são especificadas como:

[...] fases de geração, transmissão, distribuição e consumo, incluindo as etapas de projeto, construção, montagem, operação, manutenção das instalações elétricas e quaisquer trabalhos realizados nas suas proximidades, observandose as normas técnicas oficiais estabelecidas pelos órgãos competentes e, na ausência ou omissão destas, as normas internacionais cabíveis (Brasil, 2004, p. 1).

Vale ressaltar o indicado no item 10.8, da Norma NR 10, intitulado "Habilitação, Qualificação, Capacitação e Autorização dos Trabalhadores", em que são especificadas as possibilidades de capacitação por competência (Brasil, 2004, p. 5):

10.8.3 É considerado trabalhador capacitado aquele que atenda às seguintes condições, simultaneamente:

a) receba capacitação sob orientação e responsabilidade de profissional habilitado e autorizado; e

b) trabalhe sob a responsabilidade de profissional habilitado e autorizado.

10.8.3.1 A capacitação só terá validade para a empresa que o capacitou e nas condições estabelecidas pelo profissional habilitado e autorizado responsável pela capacitação.

10.8.4 São considerados autorizados os trabalhadores qualificados ou capacitados e os profissionais habilitados, com anuência formal da empresa.

A pesquisa sobre a qual elaboramos reflexões teve como objeto a formação prática não teórica dos operários nos cenários da investigação, avaliada por meio da constituição do saber do trabalhador na execução das tarefas do trabalho (ou construção do seu conhecimento técnico), acarretando o aprofundamento sobre saberes e práticas constituídos. Para compreender o conhecimento do "professor-engenheiro" e do "alunotrabalhador" durante o processo de construção da aprendizagem, observamos o que nos diz Freire (1996, p. 24):

[...] o educando precisa se assumir como tal, mas, ao assumir-se como educando significa reconhecer-se como sujeito que é capaz de conhecer e que quer conhecer em relação com outro sujeito igualmente capaz de conhecer, o educador e, entre os dois, possibilitando a tarefa de ambos, o objeto do conhecimento. Ensinar e aprender são assim momentos de um processo maior - o de conhecer, que implica re-conhecer. 
O conhecimento do engenheiro tem origem nos "espaços acadêmicos", de nível superior, e a ele é atribuído um título institucional. O conhecimento do trabalhador provém da prática, da resolução de problemas. O "título" do engenheiro provém da "universidade"; já o do trabalhador lhe será atribuído pela competência e habilidade do "fazer".

Essa concepção sobre constituição de saberes está presente no pensamento de Fiorentini (1995, p. 28 apud D'Ambrosio, 1993, p. 6-9), com relação à adoção de novos caminhos para a educação. Estes caminhos não seriam somente os instituídos pelas academias como cita o autor "Isso implica também, uma revisão crítica de teorias correntes de cognição, epistemológica, histórica e política."

A proposta etnomatemática ao permitir atribuir significados aos saberes dos operários, aos saberes fora dos espaços formais de formação e qualificação cria condições para uma explicação de como se relaciona as competências profissionais com as competências instrucionais. Observamos isto, como indicado por Blanco (2008, p. 22), na entrevista concedida por Ubiratan D'Ambrosio a Revista Latino Americana de Etnomatemática ( ${ }^{\circ}$ 1, fevereiro, 2008). A resposta de D'Ambrosio indica que a metodologia recomendada para trabalhar em etnomatemática consiste em "Observação das práticas de grupos ou população diferenciadas [...]” prossegue D’Ambrosio: “[...] então um método de trabalho em etnomatemática é uma observação da prática de grupos naturalmente diferentes, possibilitando ver o que fazem e como fazem, assim como fazer uma narrativa de suas práticas e depois analisar o discurso."

A proposta etnomatemática de D’Ambrosio (2008) é empregada por Fiorentini (1995, p. 25), quando menciona construir, classificar, ordenar, intervir e modelar. Esta foi a proposta metodológica adotada na pesquisa, por permitir reconhecer os "saberes de experiência feitos", dos operários.

Para D’Ambrósio (1990, p. 5) “ [...] etnomatemática é a arte ou a técnica de explicar, de conhecer, de entender nos diversos contextos culturais." (D’Ambrosio, 1990, p. 5). Esta perspectiva indica a possibilidade de se resgatar saberes de diferentes grupos nos seus contextos culturais- operários, índios, povos minoritários, raças não ocidentais etc.. O espaço de desenvolvimento proximal da construção destes saberes ocorre quando as práticas acontecem a partir de (em cima de) situações problemas compreendidas e solucionadas por estes grupos.

Considerar a proposta etnomatemática no desenvolvimento da pesquisa utilizou-se o descrito por Latorre (2008, p. 5), que relaciona a etnomatemática e as danças religiosas no norte do Chile na festa em homenagem a N. ${ }^{a}$ S. ${ }^{a}$ do Carmo (Virgen del Carmen), denominada La fiesta de La Tirana, en el pueblo de La Tirana, comuna de Pozo Almonte, Región de Tarapacá. Afirma a autora: 'El explicar, entender y relacionar es el 'matema' y la utilización de símbolos corporales es el 'tica'. Así se procura entender los 'ticas' de 'matema' en el 'etno' chileno; en consequência buscamos la relación entre las coreografías de esas danzas y las transformaciones geométricas." Aplicando-se estes conceitos ao objeto e objetivos deste trabalho, pode-se dizer que "matema" é relativa às tarefas desenvolvidas pelos operários, constituindo-se do explicar a tarefa desenvolvida, entender como essa tarefa se desenvolve e estabelecer a relação com os conceitos matemáticos utilizados pelos operários. A utilização dos saberes matemáticos é a "tica". Assim se procura entender as “ticas" de "matema" no "etno" destes operários. Em consequência, busca-se a relação 
entre o modo de desenvolver as tarefas de engenharia pelos operários e as operações matemáticas.

\section{Considerações Finais}

Adultos trabalhadores vivenciam a formação durante e no trabalho para conseguirem o desenvolvimento nas tarefas do corpo da especialização da manutenção das redes elétricas, relacionadas às engenharias elétrica, mecânica, hidráulica e construção civil. Realizam essas ações com alegria, seriedade, orgulho, assertividade, objetividade, humildade e boas práticas técnicas. A pesquisa propiciou identificar os esforços para a construção de saberes necessários à realização de tarefas de manutenção programada e, principalmente, eventos não programados e que surgem durante essa execução. Idêntica construção de saberes acontece durante os serviços de atendimento emergencial nas instalações da concessionária de energia elétrica, quando ocorrem os defeitos elétricos, mecânicos e civis.

A leitura e a análise da legislação referente à formação de adultos trabalhadores permitiram identificar que tal formação pode acontecer " [...] em articulação com o ensino regular ou por diferentes estratégias de educação continuada, em instituições especializadas ou no ambiente de trabalho" (Brasil, 1996) - o que dá respaldo a uma formação que utilize e suscite a valorização de saberes não escolares.

Considerando que os sujeitos da pesquisa são adultos trabalhadores que despendem longos períodos de suas vidas no espaço do trabalho, portanto, confrontam-se cotidianamente com o desgaste físico, com o cansaço, pode-se afirmar que a formação durante e (no) trabalho é a única possibilidade de reconhecer saberes. Estes, cujas ações se dão no trabalho e para o trabalho, são valorizados no campo da educação profissional como previsto em legislação (artigos 40 e 41 da LDBEN n. ${ }^{\circ} 9.394 / 96$, parágrafo IV; artigos $1 .^{\circ}$ e $2 .^{\circ}$ do Decreto n. ${ }^{\circ}$ 2.208, de 17.04.1997). 


\section{Referências}

Alexim, J.C.; Brígido, R.(2002). Certificação de competências profissionais: glossário de termos técnicos. Brasília: OIT, $40 \mathrm{p}$.

Alexim, J.C.; Bellan, A.C.D.; Dias, J. (Orgs.) (2002). Referencial de planejamento: diversidade e educação profissional. Brasília: OIT, 56 p. [Colaboração de Lucienne Freire].

Alexim, J.C.; Lopes, C.L.E. (2003). A certificação profissional revisitada. Boletim Técnico do SENAC, Rio de Janeiro, v. 29, n. 3, set./dez. p. 8-19. Disponível em: < http://www. senac.br/BTS/293/boltec293a.htm>. Acesso em: 29 jun. 2008.

Blanco, H. A.; D'Ambrosio, U. (2008). Entrevista al profesor Ubiratan D'Ambrosio. Buenos Aires, 2004, VI Congreso de Historia de las Ciencias y la Tecnología. In: La Revista Latinoamericana de Etnomatemática (RLE) - Vol. 1, n. 1, Fev. 2008. Disponível em: <http://www.etnomatematica.org/v1-n1-febrero2008/blanco.pdf>. Acesso em: 22.9.2008.

Brasil (1996). Presidência da República. Casa Civil. Subchefia para Assuntos Jurídicos. Lei n. ${ }^{\circ}$ 9.394, de 20 de dezembro de 1996. Estabelece as diretrizes e bases da educação nacional. Diário Oficial [da] República Federativa do Brasil, Brasília, DF, 23 dez. 1996. Seção 1, p. 27833.

Brasil (2004). Presidência da República. Casa Civil. Subchefia para Assuntos Jurídicos. Decreto n. ${ }^{\circ} 5.154$, de 23 de julho de 2004. Regulamenta o $\S 2 .^{\circ}$ do art. 36 e os arts. 39 a 41 da lei n. ${ }^{\circ} 9.394$, de 20 de dezembro de 1996, que estabelece as diretrizes e bases da educação nacional, e dá outras providências. Diário Oficial [da] República Federativa do Brasil, Brasília: DF, 26 jul. 2004.

Brasil (2005). Ministério do Trabalho e Emprego. NR-10: segurança nas instalações e serviços em eletricidade. Diário Oficial [da] República Federativa do Brasil, Brasília: DF.

Brasil (2007). Comitê Nacional de Educação em Direitos Humanos. Plano Nacional de Educação em Direitos Humanos. Brasília: Secretaria Especial dos Direitos Humanos, Ministério da Educação, Ministério da Justiça, UNESCO.

Brasil (2008). Ministério da Educação. Secretaria de Educação Profissional e Tecnológica. Catálogo nacional de cursos técnicos. Brasília: MEC/SEPT, 2008. Disponível em: $<$ _http://portal.mec.gov.br/setec/arquivos/pdf3/catalogo_tecnicos.pdf>. Acesso em: 17.07.2009.

Cêa, G.S. dos S. (2006). A reforma da educação profissional e o ensino médio integrado: tendências e riscos. In: ASSOCIAÇÃO NACIONAL DE PÓS-GRADUAÇÃ̃O E PESQUISA EM EDUCAÇÃO, 29., 2006, Curitiba. Anais... Curitiba: ANPED. GT Trabalho e Educação n. 9.

D’Ambrosio, U. (1990). Etnomatemática - Arte ou técnica de explicar ou conhecer. São Paulo: Ática.

Fiorentini, D. (1995). Alguns modos de ver e conceber o ensino da matemática no Brasil. Campinas: Zeteiké, Ano 3, n. ${ }^{\circ}$ 4, p. 24-37.

Freire, P. (1996). Pedagogia da autonomia: saberes necessários à prática educativa. 7. ${ }^{\text {a }}$ ed. São Paulo: Paz e Terra. 
Latorre, L. D. (2008). Danzas Religiosas: ¿Alguna Relación Con la Matemática? Valparaíso de Chile, 111 f. Tesis Magister en Enseñanza de las ciencias, mención Didáctica de las Matemáticas. Pontificia Universidad Católica de Valparaíso.

Rocha, J.C. (2004). Contribuição do projeto Unicidadania ao parecer sobre a profissionalização e certificação profissional baseada em competências de agentes de direitos humanos e cidadania. Salvador: Associação de Advogados de Trabalhadores Rurais no Estado da Bahia/Fundação Joaquim Nabuco/Movimento Leigo para América Latina (MLAL), p. 2-8. Disponível em: <http://www.fundaj.gov.br/geral/unicida/ textos/documento_certificacao.pdf>. Acesso em: 29.06. 2008. 